\title{
Repair of Fire Damaged Axially Loaded Short RC Columns Using GFRP Wrap
}

\author{
L. N. K. Sai Madupu ${ }^{1, *}$, K. S. Sai Ram ${ }^{2}$ \\ ${ }^{1}$ Acharya Nagarjuna University, Guntur, Andhra Pradesh, India \\ ${ }^{2}$ Department of Civil Engineering, R.V.R \& J.C College of Engineering, Guntur-522019, Andhra Pradesh, India
}

Received July 26, 2021; Revised August 23, 2021; Accepted October 6, 2021

\begin{abstract}
Cite This Paper in the following Citation Styles
(a): [1] L. N. K. Sai Madupu, K. S. Sai Ram, "Repair of Fire Damaged Axially Loaded Short RC Columns Using GFRP Wrap," Civil Engineering and Architecture, Vol. 9, No. 6, pp. 2039-2054, 2021. DOI: 10.13189/cea.2021.090632.

(b): L. N. K. Sai Madupu, K. S. Sai Ram (2021). Repair of Fire Damaged Axially Loaded Short RC Columns Using GFRP Wrap. Civil Engineering and Architecture, 9(6), 2039-2054. DOI: 10.13189/cea.2021.090632.
\end{abstract}

Copyright $\bigcirc 2021$ by authors, all rights reserved. Authors agree that this article remains permanently open access under the terms of the Creative Commons Attribution License 4.0 International License

\begin{abstract}
Fire damaged columns can be repaired with glass fibre reinforced polymer (GFRP) wrap to regain its full strength or even more. In the present work, short reinforced concrete (RC) rectangular columns which are exposed to elevated temperature at $400^{\circ} \mathrm{C}$ for 2 hours duration are repaired using GFRP wrap glued with epoxy resin. Strengthening of existing columns using GFRP wrap is a simple, easy and economical solution. GFRP wrap enhances the stiffness of the column in lateral direction, which improves the load carrying capacity of the column. The behaviour of GFRP wrapped column is different from the behaviour of column without GFRP wrap in response to the applied load. The behavior of GFRP strengthened column depends on various factors such as column cross sectional area aspect ratio, radius of rounded edges of the column, number of GFRP layers wrapped, width of GFRP strip, wrap pattern, epoxy properties etc. Various wrap patterns are tried to obtain effective one which greatly enhances the load taking capacity of short axially loaded columns. GFRP wrapping using strips showed good results than using continuous layer. The load carrying capacity of fire damaged GFRP repaired columns is increased by $42.3 \%$ compared with undamaged column without GFRP wrap and increased by $112.6 \%$ compared with fire damaged column without GFRP. Designer should fairly estimate the capacity of the strengthened column. Mathematical models are developed to predict the strength of repaired columns.
\end{abstract}

Keywords Columns, Elevated Temperature, Epoxy Resin, GFRP Wrap, Repair

\section{Introduction}

The properties of concrete, reinforced steel and bond between them of an R.C. element subjected to elevated temperature are affected considerably. Elastic modulus, compressive strength, tensile strength, stress-strain behaviour are some of the important mechanical properties which are affected due to the disturbance caused in chemical composition, mass loss, bond between constituent materials. Also, the extent of damage mainly depends on various factors such as temperature level, time of exposure, moisture content in the concrete, constituent materials of concrete, method used to put off fire etc.

The various physical damages include micro cracking, spalling of concrete, loss of bond between concrete and reinforcement, loss of hardness, loss of toughness etc. The restoration of lost chemical and mechanical properties of concrete and reinforcing steel is not practically possible. But load carrying capacity of RC structural elements which are damaged due to fire can be restored by various repair techniques. Repair with FRP wrapping is one of the most successful techniques as working with FRP is simple and easy. Repair with R C Jacket needs more working space and proper shuttering which increases the cost of repair. Repair with steel jacket needs skilled labour and also have construction difficulties. While repairing RC columns with FRP, a smooth finish of surface is needed without any undulations and point outs. Entrapped air bubbles should be removed to ensure proper sticking of FRP with the column surface. There is considerable decrease in compressive strength of concrete which is exposed for 2 hours duration to fire at a temperature of 
$400^{\circ} \mathrm{C}$

Previously, M. Yaqub et al. [1] studied stress-strain behaviour of heated square columns repaired with GFRP and CFRP and determined significant enhancement in strength, ductility and strain properties. Tan et al. [2] studied the effect of elevated temperature on concrete columns deterioration in terms of strength, stability etc. Maraveas et al. [3] discussed the performance of bond between epoxy and FRP reinforcement under high temperature. Liu Lixian et al. [4] explained about the models on load carrying capacity of strengthened column after exposure to high temperature. Moudar et al. [5] explained the possibility of failure with time of RC columns exposed to high temperature and it is concluded that under high temperature, the material properties of steel reinforced concrete degrade radically. Firmo et al. [6] reviewed the fire performance of FRP strengthed RC structural elements. Yaman et al. [7] studied the effectiveness of using fabrics in repair of RC columns damaged by exposing to high temperatures. Sai et al. $[8,9]$ investigated the behaviour of RC rectangular columns strengthened with GFRP strips. Lam [10], Chen [11] and Alper et. al. [12] proposed a model on stress-strain behaviour of concrete columns strengthened with FRP. Silva et al. [13] worked on concrete cylinders of different length/diameter ratio. Erdemli [14], Manish [15] and Parvin et al. [16] studied the stress-strain behaviour of the columns having different shapes. Manesh [17] and Promis et al. [18] used FRP straps to confine concrete. Antonio et al. [19] studied the confinement pressure variation with cross section. Benzaid et al. [20] deliberated factors such as number of FRP sheets wrapped and rounding of edges using square plain concrete columns. Silvia [21] and Toutanji et al. [22] proposed a model to estimate the load carrying capacity of FRP strengthened columns. Omar et al. [23] studied the effect of stiffness on strength of CFRP repaired columns. Fonseca [24] and Mukhtar et al. [25] studied the effectiveness of FRP sticking on concrete surface. Wang et.al. [26] concluded that the rupture strain of FRP affects the performance of confined concrete with FRP. Manar et al. [27] studied the effect of fire on carrying capacity of CFRP confined concrete.

The literature available on rectangular R.C. columns of different aspect ratios repaired with FRP strips wrapped in several patterns is very skimp. The performance of staggering of strips is not studied previously. An elaborated study with different cross section area aspect ratios of rectangular column, different widths of FRP strips and various stick patterns is needed. In this paper, axially loaded short columns were subjected to a temperature of $400^{\circ} \mathrm{C}$ for two hours duration and repaired with GFRP bidirectional cloth stick with epoxy resin in different patterns. It is much complicated to develop a unified single expression to predict strength of GFRP repaired column considering all factors such as cross section aspect ratio, length of column, number of layers, width of strip, wrap pattern, corner radius etc. Hence, each wrap pattern is considered separately and mathematical models are developed to predict the load carrying capacity of GFRP repaired columns having different aspect ratio $(a / b)$ values. For each GFRP repair pattern, an equation is suggested to predict load carrying capacity (Ptr) of fire damaged GFRP repaired columns if the corresponding strength of fire damaged column with out GFRP wrapping $(\mathrm{Pt})$ is known for different aspect ratios $(\mathrm{a} / \mathrm{b})$ between 0.5 and 1 . The predicted load carrying capacities using the proposed expressions are matching well with the experimental results of the study.

\section{Materials}

OPC 53 grade in accordance with IS 12269:1987, Natural river sand having a specific gravity of 2.6 and of Zone III confirming to IS 383: 1970, Angular aggregate of $10 \mathrm{~mm}$ size having a specific gravity of 2.7 in accordance with IS 383:1970, potable water are the materials used for preparing concrete. The longitudinal reinforcement is of $10 \mathrm{~mm}$ diameter four HYSD bars. $6 \mathrm{~mm}$ diameter mild steel ties at $100 \mathrm{~mm}$ centre to centre spacing are used as transverse reinforcement in the column. GFRP cloth is bidirectional and having thickness of 180 microns. Epoxy resin having specific gravity nearly 1.2 is used as gluing agent.

\section{Experimental Procedure}

R.C. columns were cast with M30 grade concrete. Sharp edges were rounded with $15 \mathrm{~mm}$ corner radius. After 28 days of water immersed curing, the RC columns were kept idle for 7 days at room temperature to dry. Then, the column specimens were subjected to elevated temperature using an electric furnace (Figure 1). It had taken $30 \mathrm{~min}$ to reach $400^{\circ} \mathrm{C}$.

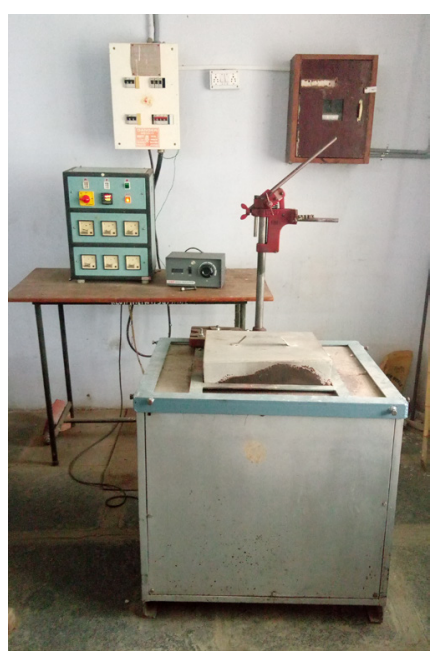

Figure 1. A view of specimens in electric furnace

The temperature level at $400^{\circ} \mathrm{C}$ was maintained for two hours. After 2 hours and 30 minutes, the electric furnace 
was put off. The columns were then allowed to cool for three days at room temperature. After surface smoothing, epoxy was applied using a brush and GFRP was glued by wrapping around the column. They were allowed to cure for three days. The columns were subjected to axial compressive load till failure (Figure 2 and 3).
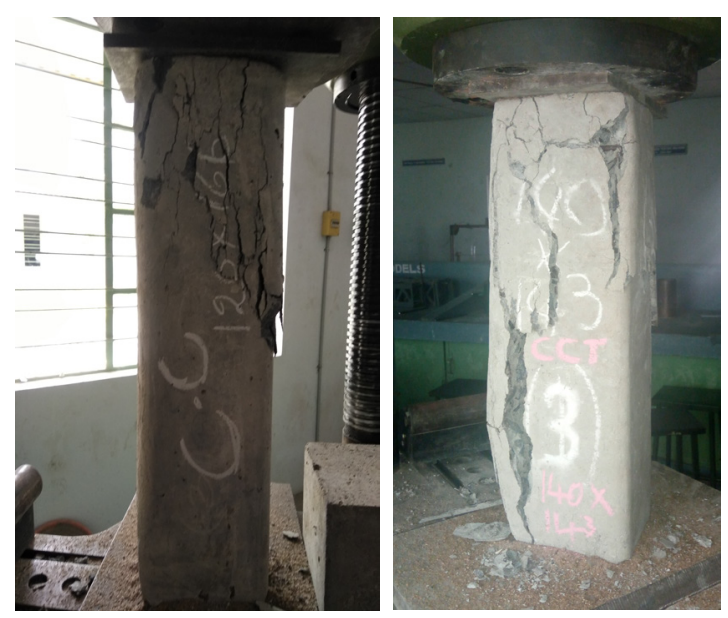

Figure 2. Failure of undamaged control column (CC) and fire damaged control column (TCC)
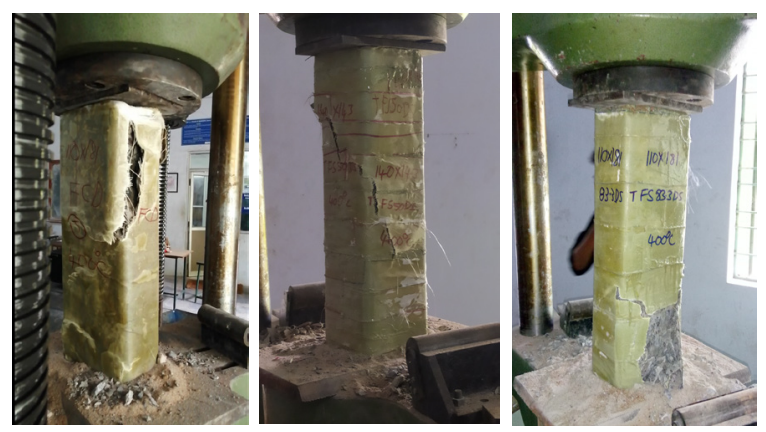

a) With full Continuous wrapping b) with $50 \mathrm{~mm}$ strips c) with $83.3 \mathrm{~mm}$ strips

Figure 3. Failure of different GFRP repaired columns (a to c)

Cross section dimensions ( $\mathrm{a} x \mathrm{~b}$ ) of the columns considered are $100 \mathrm{~mm} \times 200 \mathrm{~mm}, 110 \mathrm{~mm} \times 181 \mathrm{~mm}$, $120 \mathrm{~mm} \times 166 \mathrm{~mm}, 130 \mathrm{~mm} \times 154 \mathrm{~mm}$ and $140 \mathrm{~mm} \times$
$143 \mathrm{~mm}$. Hence, the aspect ratios $(\mathrm{a} / \mathrm{b})$ are $0.5,0.6,0.72$, 0.84 and 1 respectively. The length of column is $500 \mathrm{~mm}$ and which is the same for all columns. Various stick patterns considered are shown in Table.1. Columns wrapped in TFC pattern is shown schematically in Figure 4(a). Columns wrapped in TFS pattern with strips one over another is shown schematically in Figure 4(b). Columns wrapped in TFS pattern with staggered strips is shown schematically in Figure 4(c).

The columns are designated mainly with two series of names 'FC' and 'FS'. 'FC' columns are wrapped completely with continuous GFRP sheet without any break. 'FS' columns are wrapped completely with GFRP strips having different widths.

\section{Results and Discussion}

The ultimate loads of all columns are plotted, as shown in Figure 5a, 5b and 5c. The load-deformation curves are depicted in Figure 6 (a to o). The ratios of ultimate loads of fire damaged columns repaired with GFRP wrapping and ultimate loads of corresponding fire damaged columns without GFRP wrapping $\left(\mathrm{P}_{\mathrm{tr}} / \mathrm{P}_{\mathrm{t}}\right)$ are shown in Table 2. The ratios of ultimate loads of fire damaged columns repaired with GFRP wrapping and ultimate loads of corresponding undamaged columns not subjected to temperature $\left(\mathrm{P}_{\mathrm{tr}} / \mathrm{P}\right)$ are shown in Table 3. Mathematical models which are developed for predicting strength of GFRP repaired columns are presented in Table 4.

The axial deformations at ultimate load $(\delta)$ and related axial strains $(\varepsilon)$ are shown in Table 5 . The ratios of axial strains at ultimate load of fire damaged columns repaired with GFRP and the corresponding axial strains at ultimate load of fire damaged columns without GFRP wrapping $\left(\varepsilon_{\mathrm{tr}} / \varepsilon_{\mathrm{t}}\right)$ are presented in Table 6 . The ratios of axial strains at ultimate load of fire damaged columns repaired with GFRP wrapping and the corresponding axial strains at ultimate load of undamaged columns not subjected to temperature $\left(\varepsilon_{\mathrm{tr}} / \varepsilon\right)$ are shown in Table 7 .

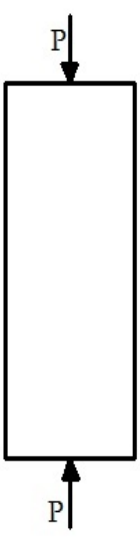

a ) TFC column
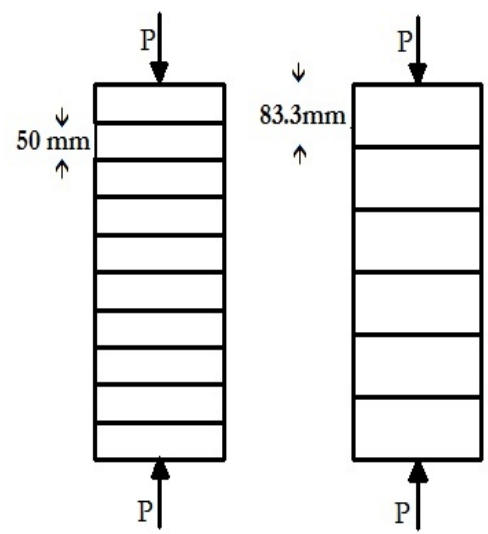

b) TFS column with strips one on another
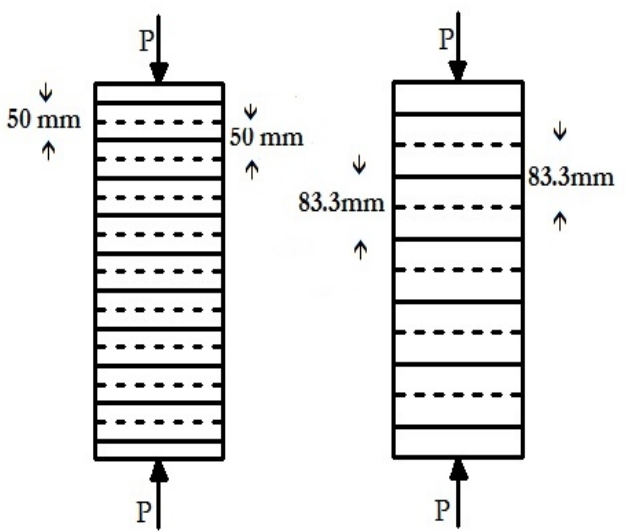

c) TFS column with staggered strips

Figure 4. Schematic drawing showing different wrap patterns (a to c) 


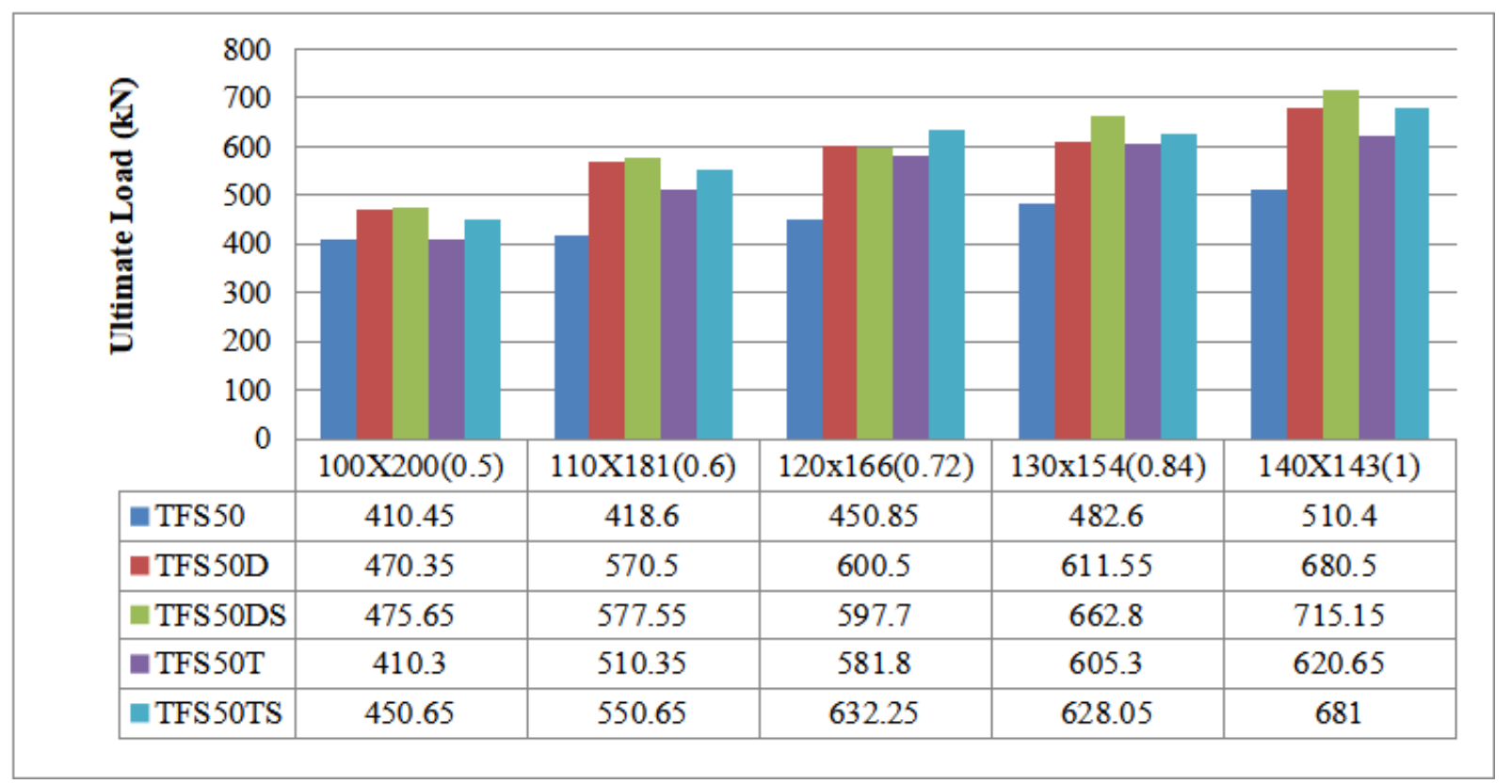

Figure 5a. Ultimate loads of CC,TCC and TFC designated columns

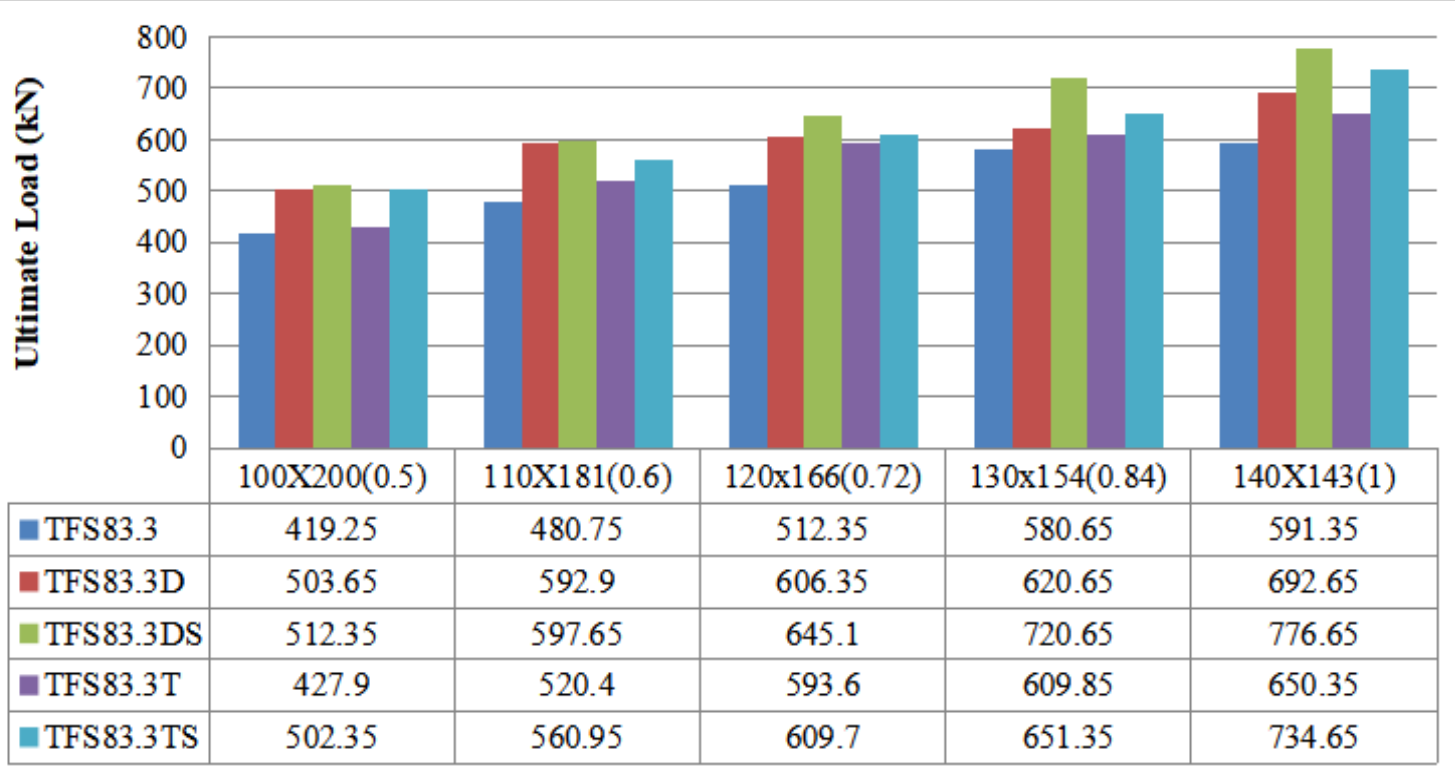

Figure 5b. Ultimate loads of TFS50 designated columns 


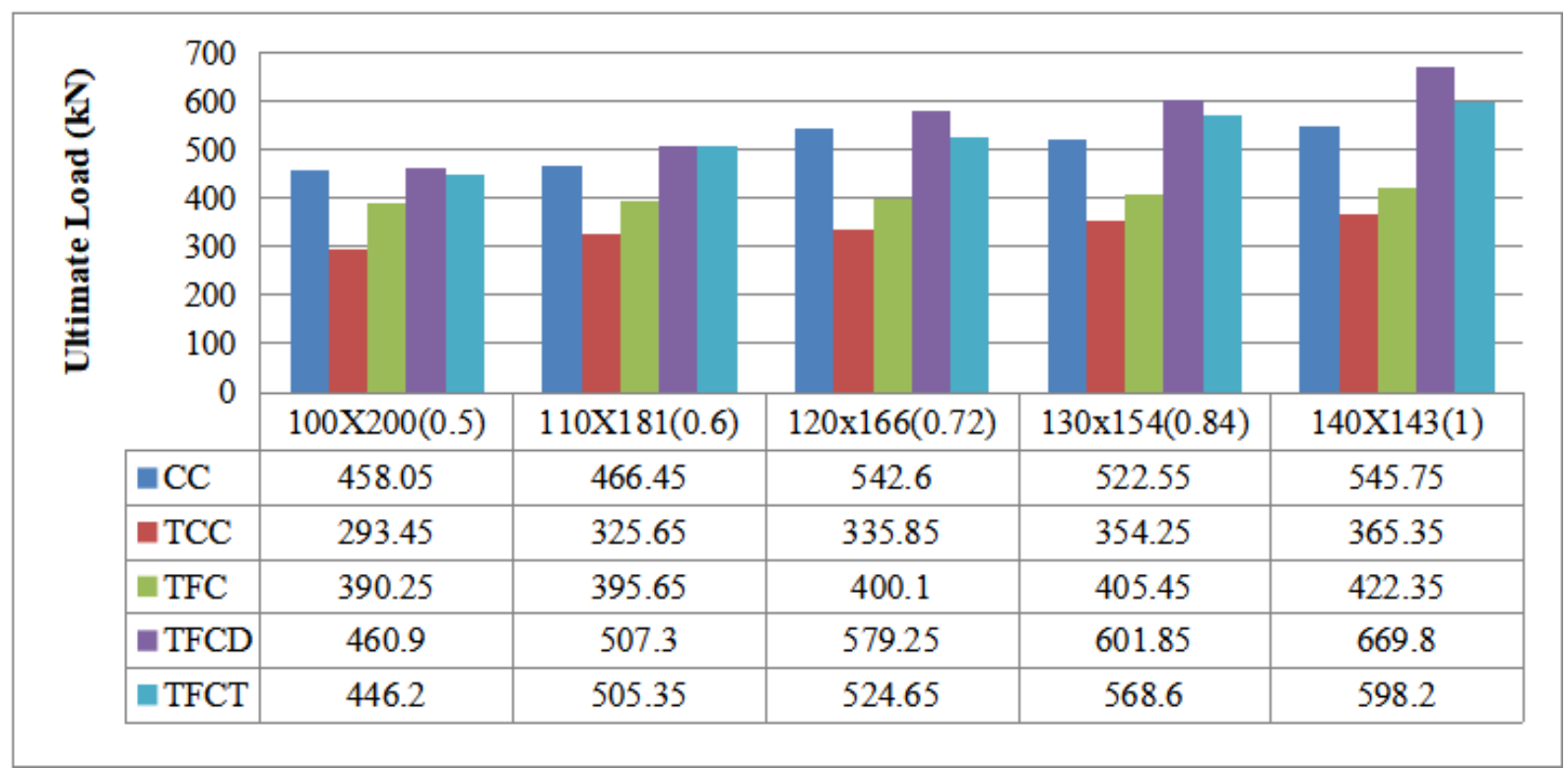

Figure 5c. Ultimate loads of TFS 83.3 designated columns

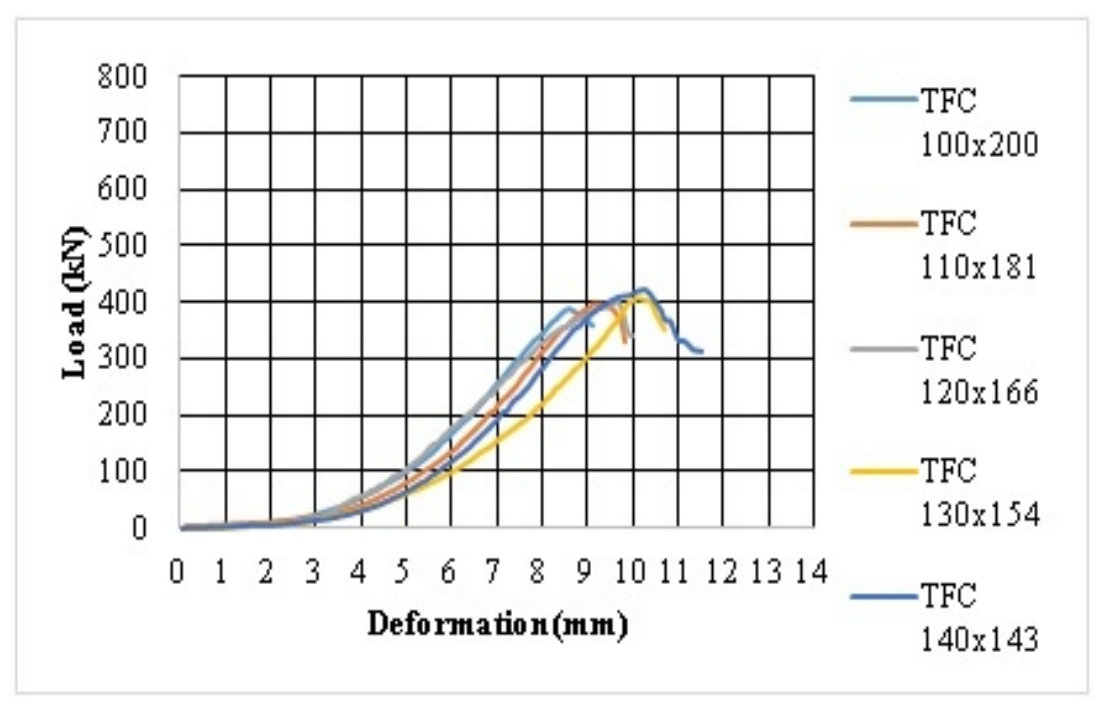

(a)

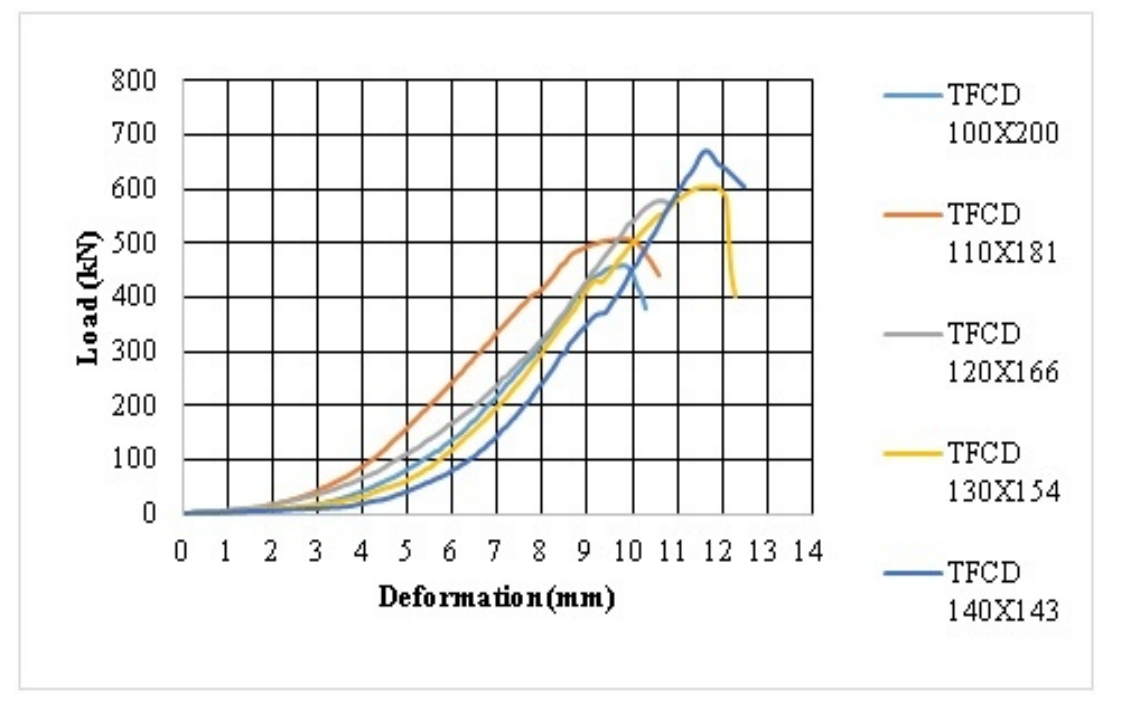



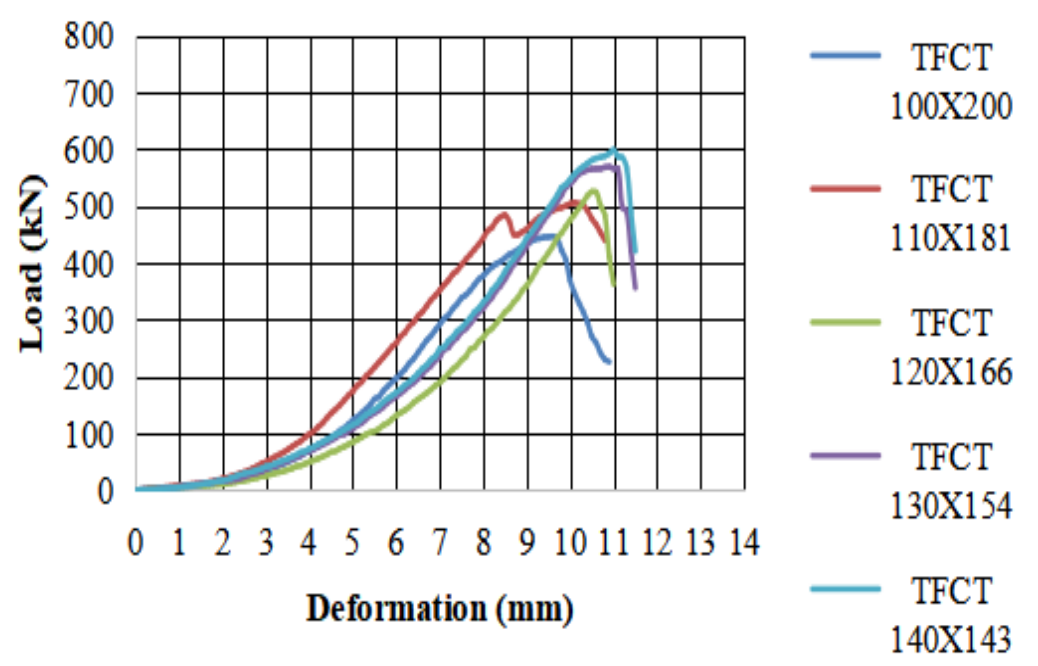

(c)

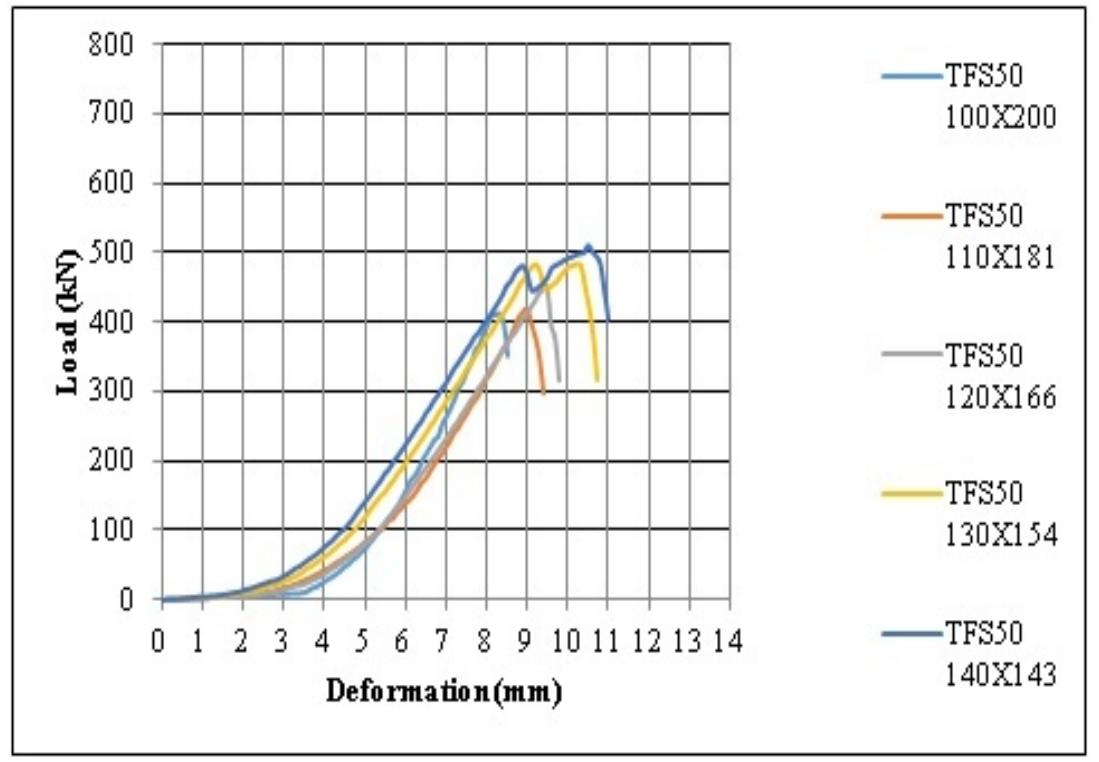

(d)

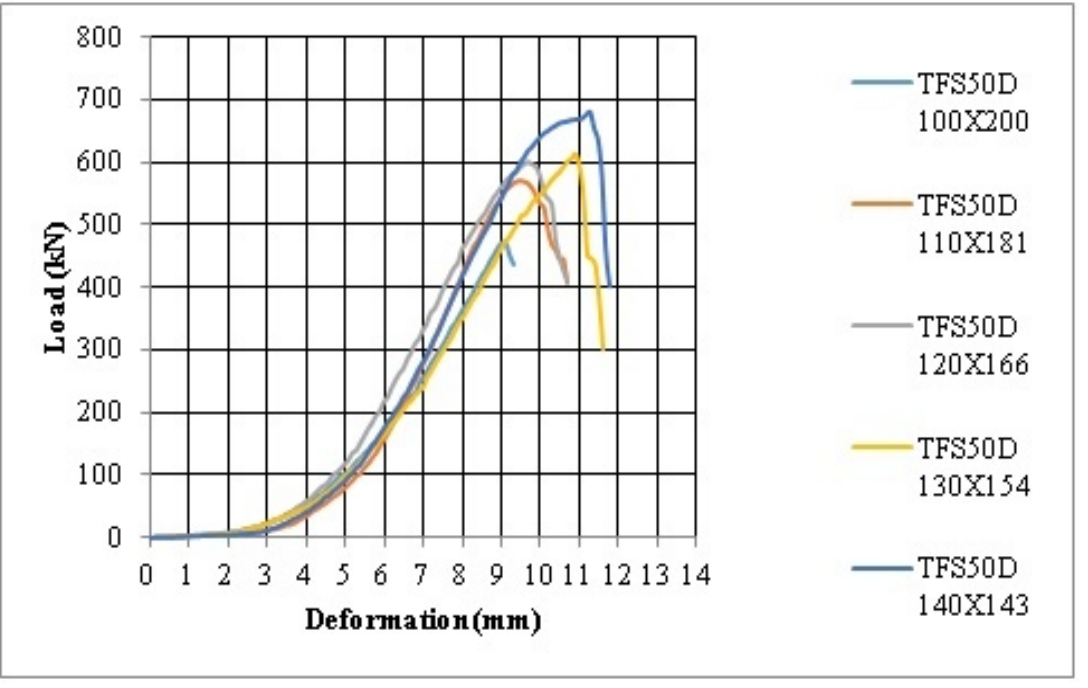

(e) 


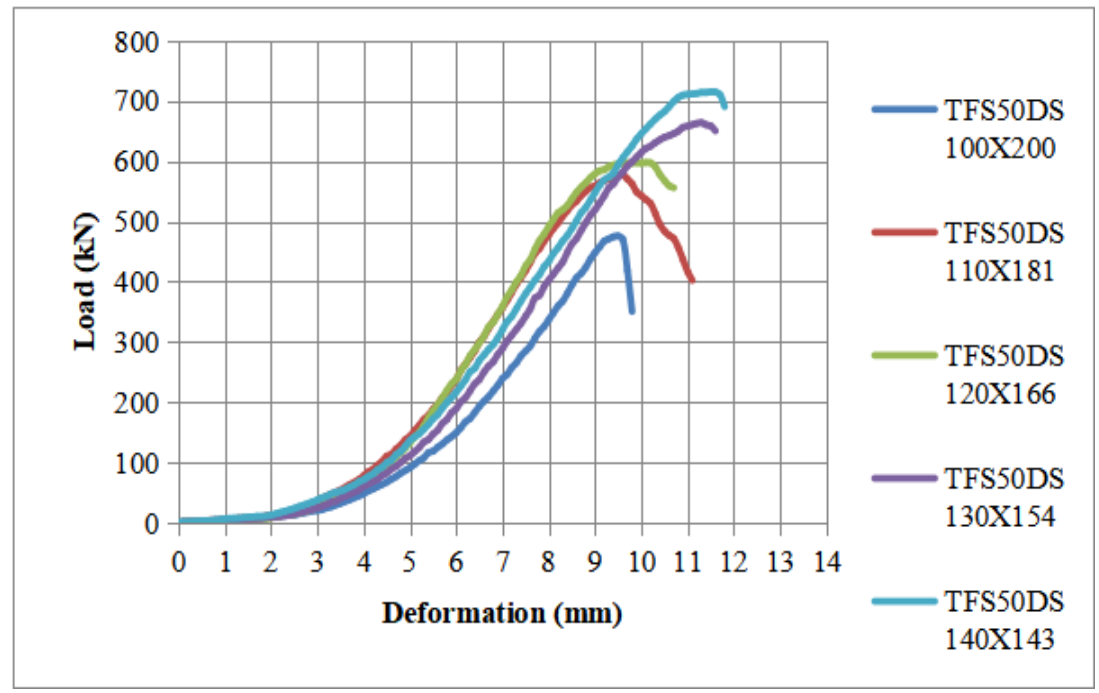

(f)

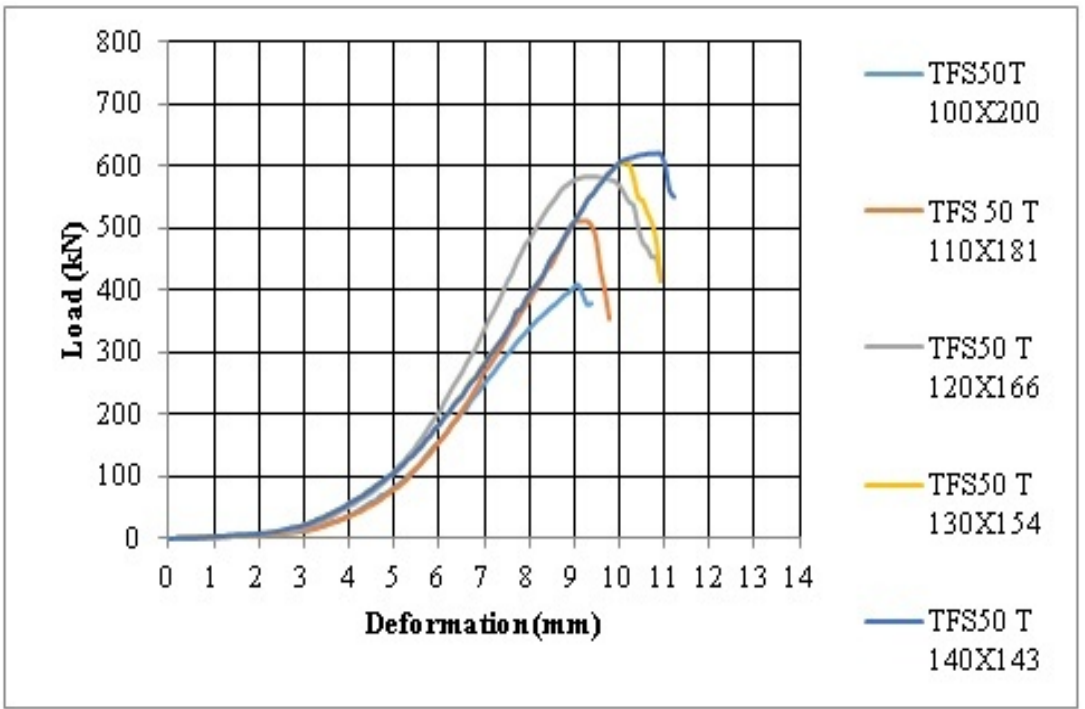

(g)

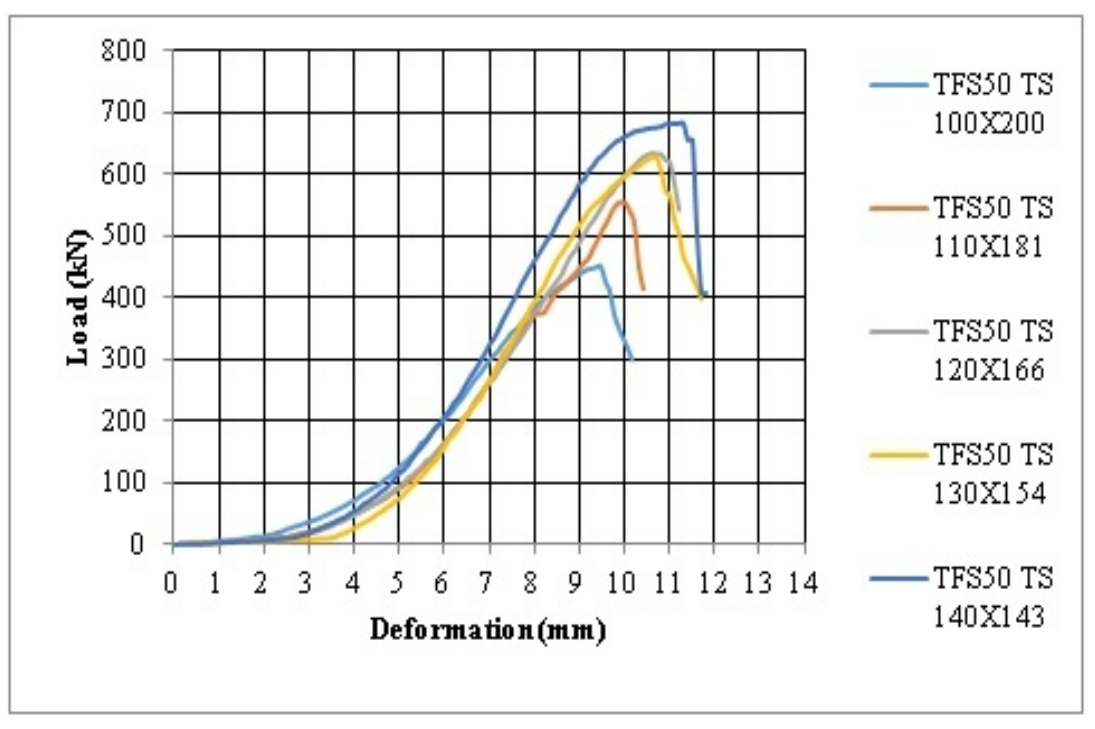




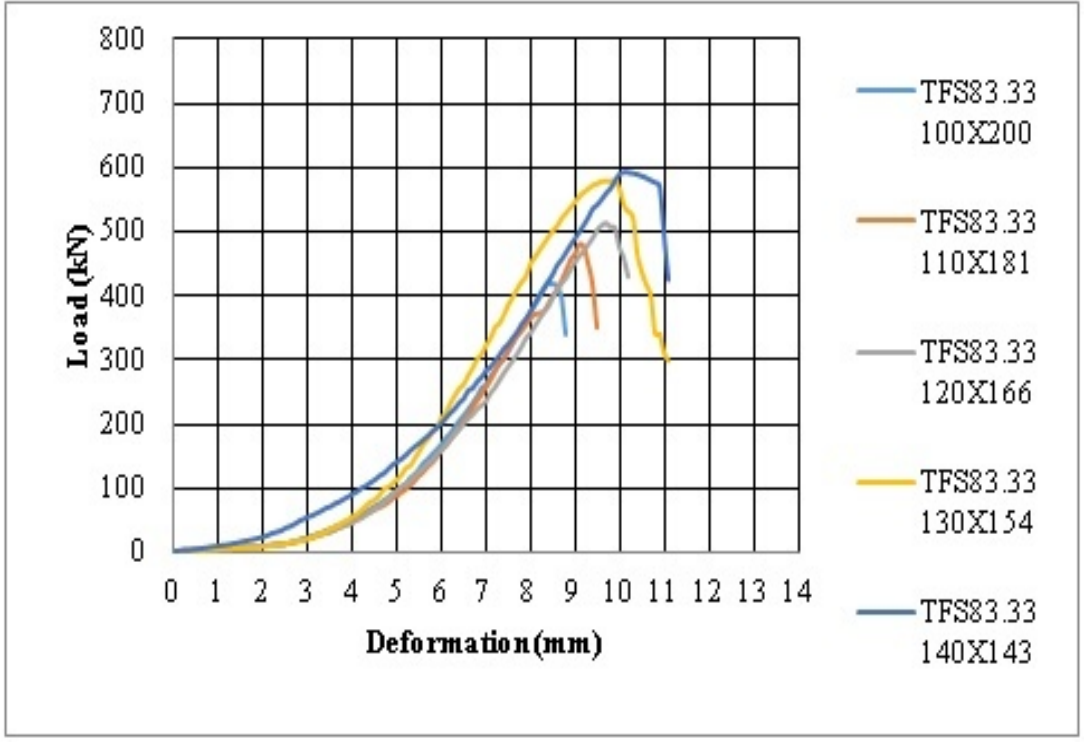

(i)

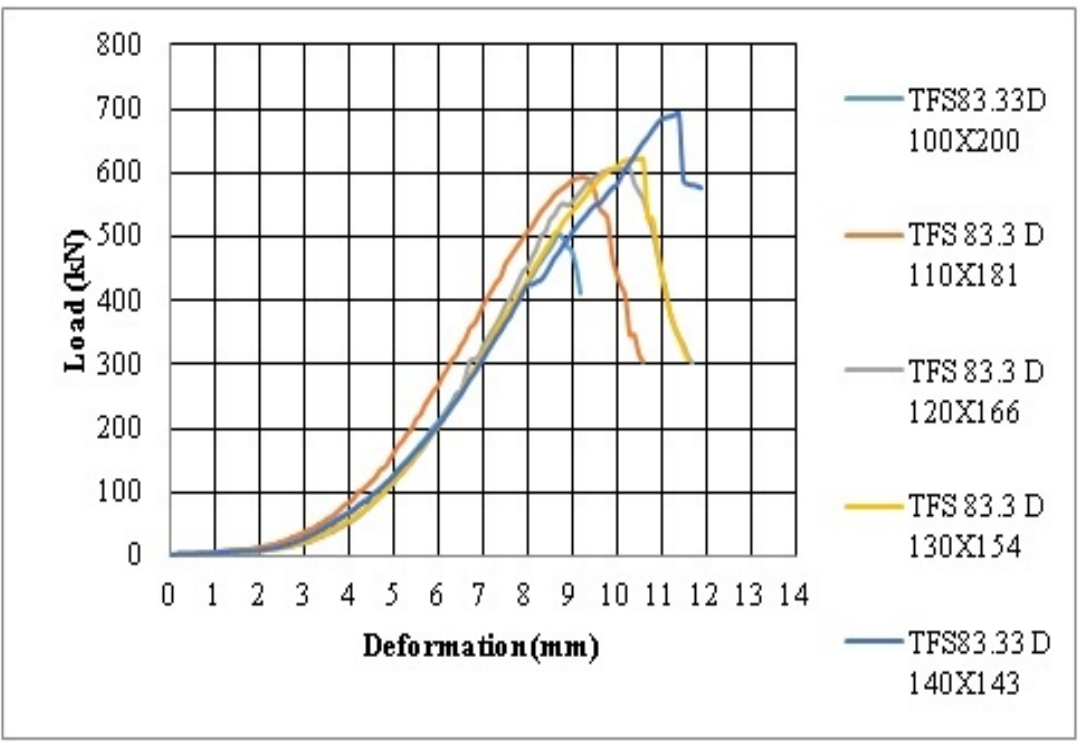

(j)

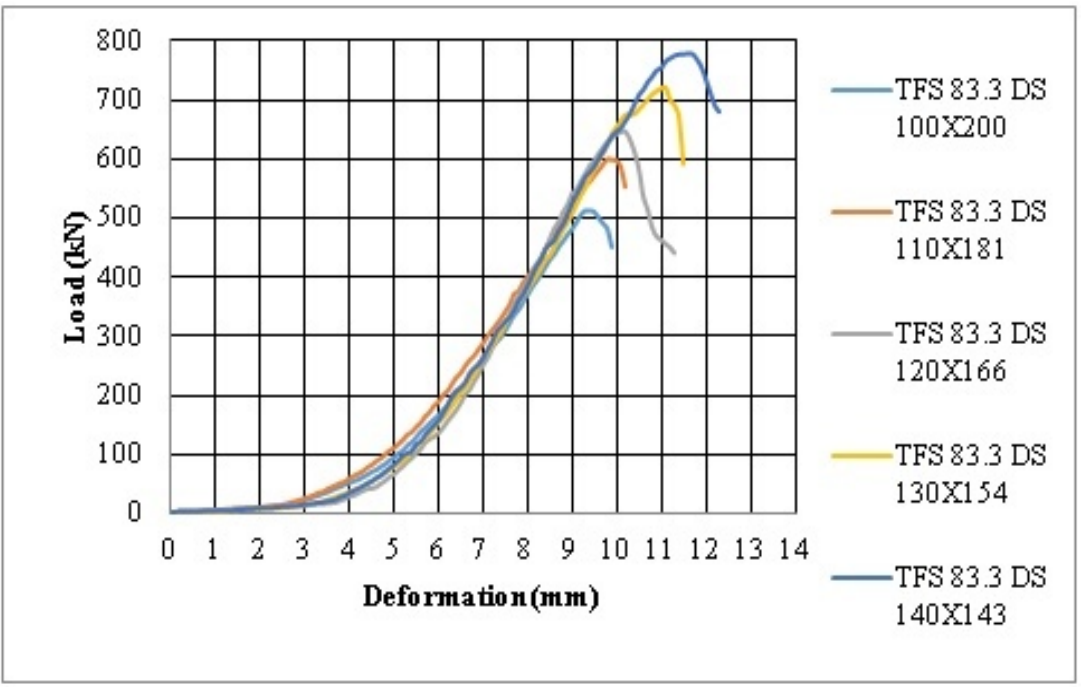




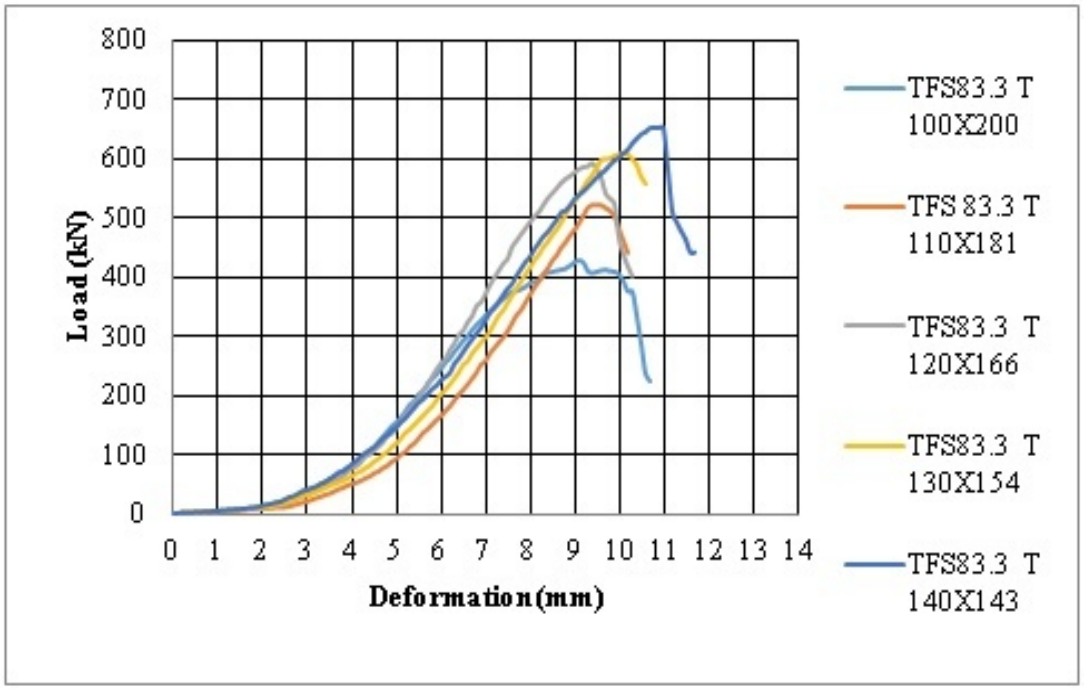

(1)

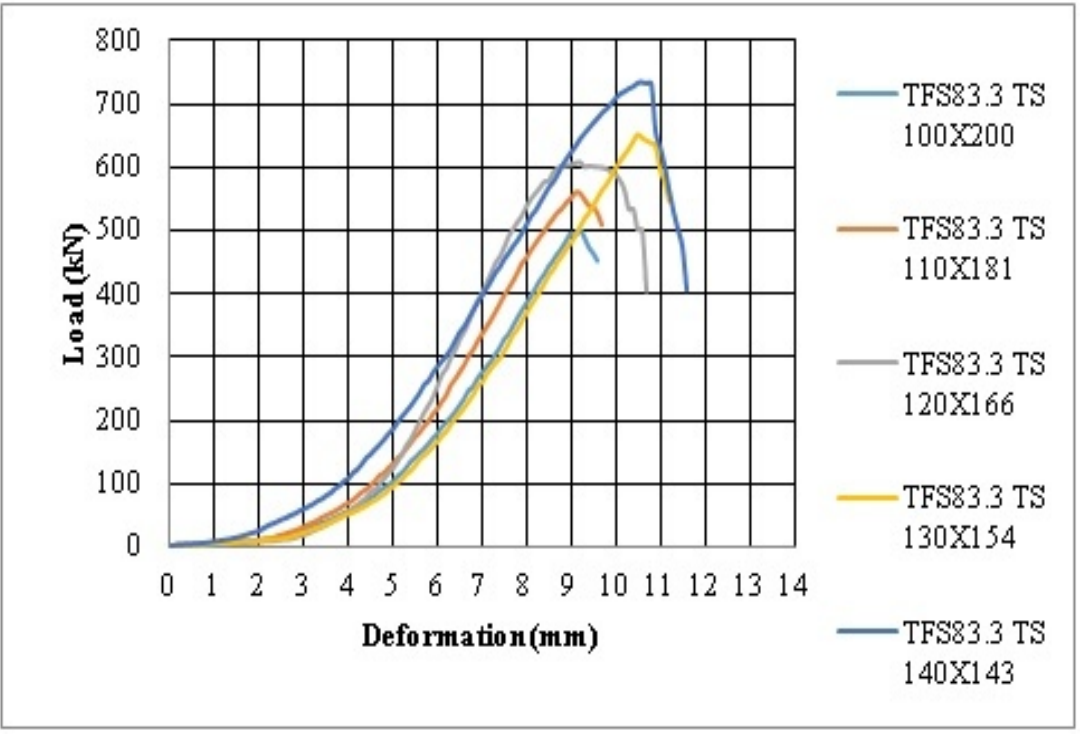

(m)

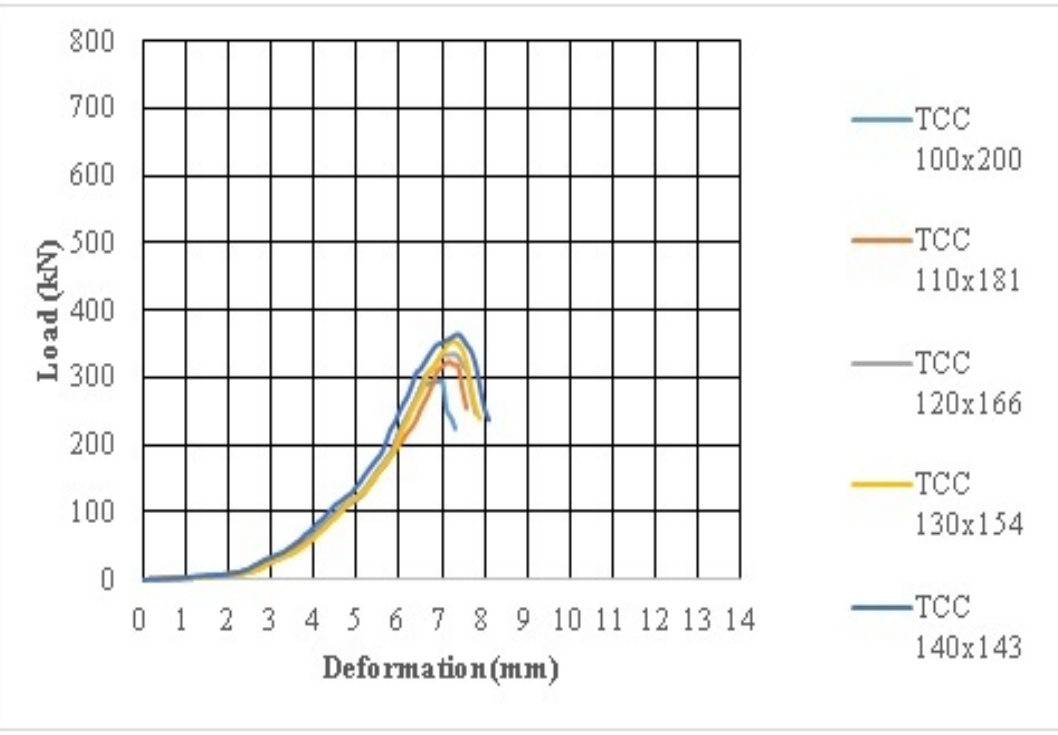

(n) 


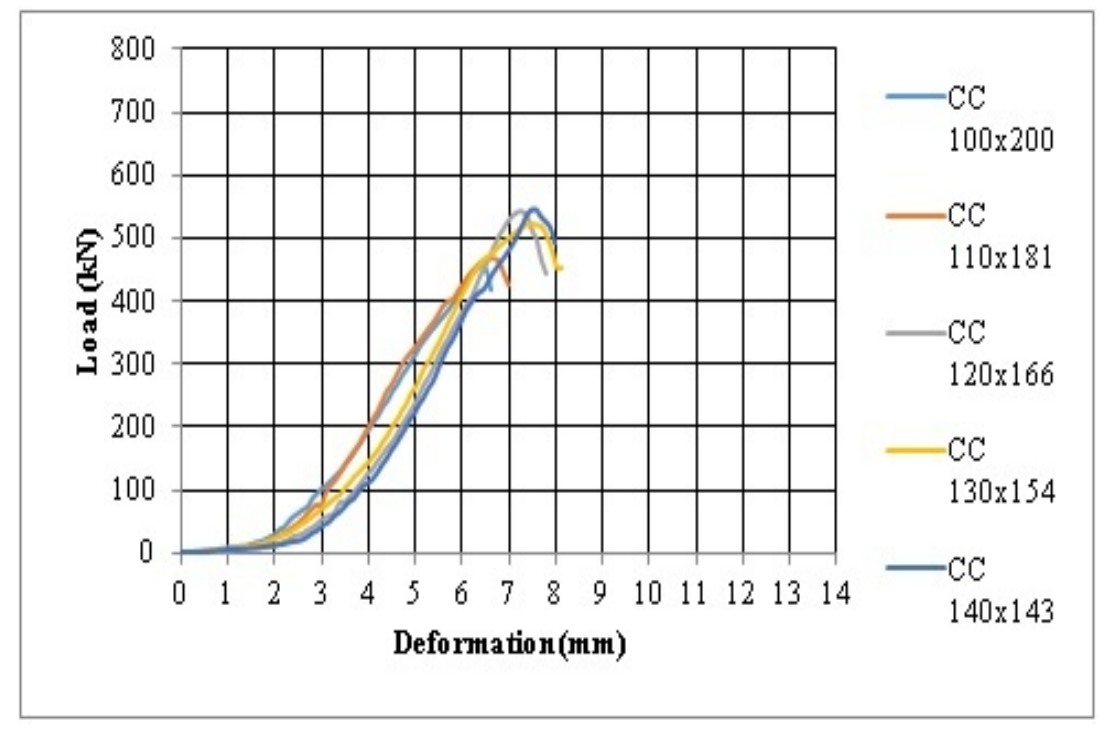

(o)

Figure 6. Load-Deformation curves of columns (a to o)

The predicted load carrying capacities of GFRP repaired columns and the percentage error compared with experimental value are presented in Table 8 .

The load carrying capacity of fire damaged columns are improved greatly by repair with GFRP wrapping. The maximum gain in load carrying capacity of fire damaged columns repaired with GFRP wrapping is observed as 2.126 times of corresponding fire damaged column without GFRP wrapping (TCC) which is for TFS83.3DS column with aspect ratio 1 (Table 2) and it is 1.423 compared with corresponding undamaged column without GFRP wrapping (CC) (Table 3).

It can be understood that there is a maximum of $112.6 \%$ increase in load carrying capacity of fire damaged GFRP repaired columns compared to fire damaged column without GFRP wrapping (TCC) and it is $42.3 \%$ compared with undamaged column without GFRP wrapping (CC), which shows that the repair with GFRP is very effective in restoring strength of fire damaged columns

The minimum regain in capacity of fire damaged columns repaired with GFRP wrapping compared with corresponding fire damaged column without GFRP wrapping (TCC) is 1.145 (Table 2), i.e. the percentage increase in capacity is $14.5 \%$ which is observed in TFC column with aspect ratio 0.84 . The minimum restoration in capacity of fire damaged columns repaired with GFRP wrapping is 0.737 times compared with corresponding undamaged column without GFRP wrapping (CC) which is observed in case of TFC column with aspect ratio 0.72 (Table 3).

Table 1. Various GFRP wrap patterns considered for the study

\begin{tabular}{|c|c|l|}
\hline Sl.No. & Notation & \\
\hline 1 & CC & Column which is not subjected to elevated temperature and not wrapped with GFRP i.e undamaged \\
\hline 2 & TCC & Column which is subjected to elevated temperature and not wrapped with GFRP i.e fire damaged \\
\hline 3 & TFC & Column is subjected to fire and fully wrapped with a continuous single layer of GFRP \\
\hline 4 & TFCD & Column is subjected to fire and fully wrapped with continuous two layers of GFRP \\
\hline 5 & TFCT & Column is subjected to fire and fully wrapped with continuous three layers of GFRP \\
\hline 6 & TFS50 & Column is subjected to fire and fully wrapped with 50 mm wide GFRP strips as single layer \\
\hline 7 & TFS50D & Column is subjected to fire and fully wrapped with 50 mm wide GFRP strips as two layers \\
\hline 8 & TFS50T & Column is subjected to fire and fully wrapped with 50 mm wide GFRP strips as three layers \\
\hline 9 & TFS50DS & Column is subjected to fire and fully wrapped with 50 mm wide GFRP strips as two staggered layers \\
\hline 10 & TFS50TS & Column is subjected to fire and fully wrapped with 50 mm wide GFRP strips as three staggered layers \\
\hline 11 & TFS83.3 & Column is subjected to fire and fully wrapped with $83.3 \mathrm{~mm}$ wide GFRP strips as single layer \\
\hline 12 & TFS83.3D & Column is subjected to fire and fully wrapped with $83.3 \mathrm{~mm}$ wide GFRP strips as two layers \\
\hline 13 & TFS83.3T & Column is subjected to fire and fully wrapped with $83.3 \mathrm{~mm}$ wide GFRP strips as three layers \\
\hline 14 & TFS83.3DS & Column is subjected to fire and fully wrapped with $83.3 \mathrm{~mm}$ wide GFRP strips as two staggered layers \\
\hline 15 & TFS83.3TS & Column is subjected to fire and fully wrapped with $83.3 \mathrm{~mm}$ wide GFRP strips as three staggered layers \\
\hline
\end{tabular}


Table 2. The ratios of ultimate loads of fire damaged columns repaired with GFRP wrapping and ultimate loads of corresponding fire damaged columns with out GFRP wrapping $\left(\mathrm{P}_{\mathrm{tr}} / \mathrm{P}_{\mathrm{t}}\right)$

\begin{tabular}{|c|c|c|c|c|c|}
\hline \multicolumn{7}{|c|}{ Cross section area aspect ratio (a/b) } \\
\hline Column identification & 0.5 & 0.6 & 0.72 & 0.84 & 1 \\
\hline TFC & 1.330 & 1.215 & 1.191 & 1.145 & 1.156 \\
\hline TFCD & 1.571 & 1.558 & 1.725 & 1.699 & 1.833 \\
\hline TFCT & 1.521 & 1.552 & 1.562 & 1.605 & 1.637 \\
\hline TFS50 & 1.399 & 1.285 & 1.342 & 1.362 & 1.397 \\
\hline TFS50D & 1.603 & 1.752 & 1.788 & 1.726 & 1.863 \\
\hline TFS50DS & 1.621 & 1.774 & 1.780 & 1.871 & 1.957 \\
\hline TFS50T & 1.398 & 1.567 & 1.732 & 1.709 & 1.699 \\
\hline TFS50TS & 1.536 & 1.691 & 1.883 & 1.773 & 1.864 \\
\hline TFS83.3 & 1.429 & 1.476 & 1.526 & 1.639 & 1.619 \\
\hline TFS83.3D & 1.716 & 1.821 & 1.805 & 1.752 & 1.896 \\
\hline TFS83.3DS & 1.746 & 1.835 & 1.921 & 2.034 & 2.126 \\
\hline TFS83.3T & 1.458 & 1.598 & 1.767 & 1.722 & 1.780 \\
\hline TFS83.3TS & 1.712 & 1.723 & 1.815 & 1.839 & 2.011 \\
\hline
\end{tabular}

Table 3. The ratios of ultimate loads of fire damaged columns repaired with GFRP wrapping and ultimate loads of corresponding undamaged columns not subjected to temperature $\left(\mathrm{P}_{\mathrm{tr}} / \mathrm{P}\right)$

\begin{tabular}{|c|c|c|c|c|c|}
\hline \multicolumn{7}{|c|}{ Cross section area aspect ratio (a/b) } & 0.84 & 1 \\
\hline Column identification & 0.5 & 0.6 & 0.72 & 0.776 & 0.774 \\
\hline TFC & 0.852 & 0.848 & 0.737 & 1.152 & 1.227 \\
\hline TFCD & 1.006 & 1.088 & 1.068 & 1.088 & 1.096 \\
\hline TFCT & 0.974 & 1.083 & 0.967 & 0.924 & 0.935 \\
\hline TFS50 & 0.896 & 0.897 & 0.831 & 1.170 & 1.247 \\
\hline TFS50D & 1.027 & 1.223 & 1.107 & 1.268 & 1.310 \\
\hline TFS50DS & 1.038 & 1.238 & 1.102 & 1.158 & 1.137 \\
\hline TFS50T & 0.896 & 1.094 & 1.072 & 1.202 & 1.248 \\
\hline TFS50TS & 0.984 & 1.181 & 1.165 & 1.111 & 1.084 \\
\hline TFS83.3 & 0.915 & 1.031 & 0.944 & 1.188 & 1.269 \\
\hline TFS83.3D & 1.100 & 1.271 & 1.117 & 1.379 & 1.423 \\
\hline TFS83.3DS & 1.119 & 1.281 & 1.189 & 1.167 & 1.192 \\
\hline TFS83.3T & 0.934 & 1.116 & 1.094 & 1.246 & 1.346 \\
\hline TFS83.3TS & 1.097 & 1.203 & 1.124 & & \\
\hline
\end{tabular}

Full continuous GFRP wrapping (FC) is less effective in restoring the capacity than full wrapping with GFRP strips (FS). Rapid propagation of local failure initiation can be prevented by using strips instead of continuous cloth of GFRP (Figure 3). In the case of FC columns, the failure pattern is like a straight line (Fig 3a) but in case of FS columns the failure pattern is in stepped pattern (Figure 3b, 3c) which indicates that the strips cut off the rapid propagation of local failure. The staggering of strips has got further advantage than sticking of strips one over another when the number of layers are more than one.

The load carrying capacity of columns bonded with double layers is more than those of bonded with single layer or triple layers. When the layers of GFRP are bonded with epoxy resin, the thickness of GFRP layer is merely increased making it a thick single sheet of GFRP. But triple layers sticking are better than single layer sticking (Table 2 and 3 ).

Compared with $50 \mathrm{~mm}$ wide strip, $83.3 \mathrm{~mm}$ strip sticking is better for increased load carrying capacity of columns (Table 2,3). The load carrying capacity of TFS83.3 series columns is more than that of TFS50 series columns (Figure $5 \mathrm{~b}, 5 \mathrm{c}$ ). In all strengthened patterns, if aspect ratio of column is increased then the effectiveness of strengthening will increase. The strengthening with GFRP wrapping is more effective in case of square column.

The load-deformation curves of fire damaged GFRP repaired columns are more steeper than those of corresponding fire damaged columns without GFRP wrapping (TCC) which indicates that the deformations at the same load is less for fire damaged GFRP repaired column than that of corresponding fire damaged column without GFRP wrapping (TCC) (Figure 6). Therefore the confinement of concrete in lateral direction is effective.

The values of deformations at ultimate load of fire damaged GFRP repaired columns are higher than those of the corresponding $\mathrm{CC}$ or TCC columns without GFRP (Table 5). It shows that the fire damaged GFRP repaired 
columns are more malleable than the control column but the ultimate failure is sudden. The value of axial strains at ultimate load of fire damaged GFRP repaired columns varies in between 0.0166 to 0.0236 (Table 5). The ratio of axial strains of fire damaged GFRP repaired columns and the corresponding axial strains of fire damaged columns without GFRP wrapping $\left(\varepsilon_{t_{r}} / \varepsilon_{t}\right)$ varies in between 1.203 and 1.616 (Table 6).

The ratio of axial strains of fire damaged GFRP repaired columns and the corresponding axial strains of undamaged columns without GFRP wrapping $\left(\varepsilon_{\mathrm{tr}} / \varepsilon\right)$ varies in between 1.278 and 1.573 (Table 7). The fire damaged column without GFRP wrapping (TCC) fails at lower strains compared with the strains of fire damaged GFRP repaired columns (Table 5). GFRP wrapping modifies the fire damaged column to rupture at higher strain than that of corresponding fire damaged column with out GFRP wrapping (TCC). It can be ascertained that the value of axial strains of fire damaged GFRP repaired columns increases as the aspect ratio $(\mathrm{a} / \mathrm{b})$ increases (Table 5).

The predicted load carrying capacity values using the proposed expressions (Table 4) are in good agreement with the experimental results. The percentage error of 57 results out of 65 results falls below $+/-5 \%$ (Table 8 ).

Table 4. Mathematical models to predict load carrying capacities of repaired columns

\begin{tabular}{|c|c|c|}
\hline $\begin{array}{c}\text { Column } \\
\text { identification }\end{array}$ & $\begin{array}{c}\text { Equation developed based on } \\
\mathrm{P}_{\mathrm{tr}} / \mathrm{P}_{\mathrm{t}} \text { values }\end{array}$ & R2 value \\
\hline TFC & $\mathrm{P}_{\mathrm{tr}}=\mathrm{P}_{\mathrm{t}}\left(1+0.1361(\mathrm{a} / \mathrm{b})^{-1.103}\right)$ & 0.8540 \\
\hline TFCD & $\mathrm{P}_{\mathrm{tr}}=\mathrm{P}_{\mathrm{t}}\left(1+0.8027(\mathrm{a} / \mathrm{b})^{0.5093}\right)$ & 0.9443 \\
\hline TFCT & $\mathrm{P}_{\mathrm{tr}}=\mathrm{P}_{\mathrm{t}}\left(1+0.6327(\mathrm{a} / \mathrm{b})^{0.2854}\right)$ & 0.9686 \\
\hline TFS50 & $\mathrm{P}_{\mathrm{tr}}=\mathrm{P}_{\mathrm{t}}\left(1+0.4032(\mathrm{a} / \mathrm{b})^{0.6267}\right)$ & 0.9545 \\
\hline TFS50D & $\mathrm{P}_{\mathrm{tr}}=\mathrm{P}_{\mathrm{t}}\left(1+0.8929(\mathrm{a} / \mathrm{b})^{0.472}\right)$ & 0.8397 \\
\hline TFS50DS & $\mathrm{P}_{\mathrm{tr}}=\mathrm{P}_{\mathrm{t}}\left(1+0.9631(\mathrm{a} / \mathrm{b})^{0.5714}\right)$ & 0.9258 \\
\hline TFS50T & $\mathrm{P}_{\mathrm{tr}}=\mathrm{P}_{\mathrm{t}}\left(1+1.2884(\mathrm{a} / \mathrm{b})^{1.671}\right)$ & 0.9914 \\
\hline TFS50TS & $\mathrm{P}_{\mathrm{tr}}=\mathrm{P}_{\mathrm{t}}\left(1+0.8738(\mathrm{a} / \mathrm{b})^{0.6219}\right)$ & 0.9160 \\
\hline TFS83.3 & $\mathrm{P}_{\mathrm{tr}}=\mathrm{P}_{\mathrm{t}}\left(1+0.7015(\mathrm{a} / \mathrm{b})^{0.7386}\right)$ & 0.9557 \\
\hline TFS83.3D & $\mathrm{P}_{\mathrm{tr}}=\mathrm{P}_{\mathrm{t}}\left(1+0.9075(\mathrm{a} / \mathrm{b})^{0.2905}\right)$ & 0.8529 \\
\hline TFS83.3DS & $\mathrm{P}_{\mathrm{tr}}=\mathrm{P}_{\mathrm{t}}\left(1+1.1327(\mathrm{a} / \mathrm{b})^{0.6015}\right)$ & 0.9971 \\
\hline TFS83.3T & $\mathrm{P}_{\mathrm{tr}}=\mathrm{P}_{\mathrm{t}}\left(1+0.8498(\mathrm{a} / \mathrm{b})^{0.7555}\right)$ & 0.7946 \\
\hline TFS83.3TS & $\mathrm{P}_{\mathrm{tr}}=\mathrm{P}_{\mathrm{t}}\left(1+0.9622(\mathrm{a} / \mathrm{b})^{0.4923}\right)$ & 0.9014 \\
\hline
\end{tabular}

Table 5. Deformations $(\delta)$ and axial strains $(\varepsilon)$ of columns

\begin{tabular}{|c|c|c|c|c|c|c|c|c|c|c|}
\hline & \multicolumn{9}{|c|}{ Cross section area aspect ratio (a/b) } \\
\hline $\begin{array}{c}\text { Column } \\
\text { identification }\end{array}$ & \multicolumn{2}{|c|}{0.5} & \multicolumn{2}{|c|}{0.6} & \multicolumn{2}{|c|}{0.72} & \multicolumn{2}{|c|}{0.84} & \multicolumn{2}{|c|}{1} \\
\hline & $\boldsymbol{\delta}$ & $\boldsymbol{\varepsilon}$ & $\boldsymbol{\delta}$ & $\boldsymbol{\varepsilon}$ & $\boldsymbol{\delta}$ & $\boldsymbol{\varepsilon}$ & $\boldsymbol{\delta}$ & $\boldsymbol{\varepsilon}$ & $\boldsymbol{\delta}$ & $\boldsymbol{\varepsilon}$ \\
\hline CC & 6.4 & 0.0128 & 6.7 & 0.0134 & 7.2 & 0.0144 & 7.5 & 0.015 & 7.6 & 0.0152 \\
\hline TCC & 6.9 & 0.0138 & 7.2 & 0.0144 & 7.3 & 0.0146 & 7.3 & 0.0146 & 7.4 & 0.0148 \\
\hline TFC & 8.6 & 0.0172 & 9.1 & 0.0182 & 9.7 & 0.0194 & 10.1 & 0.0202 & 10.2 & 0.0204 \\
\hline TFCD & 9.7 & 0.0194 & 9.9 & 0.0198 & 10.6 & 0.0212 & 11.8 & 0.0236 & 11.7 & 0.0234 \\
\hline TFCT & 9.6 & 0.0192 & 10.1 & 0.0202 & 10.5 & 0.021 & 10.9 & 0.0218 & 11.1 & 0.0222 \\
\hline TFS50 & 8.3 & 0.0166 & 9 & 0.018 & 9.5 & 0.019 & 10.2 & 0.0204 & 10.5 & 0.021 \\
\hline TFS50D & 9 & 0.018 & 9.5 & 0.019 & 9.7 & 0.0194 & 10.9 & 0.0218 & 11.3 & 0.0226 \\
\hline TFS50DS & 9.5 & 0.019 & 9.6 & 0.0192 & 10.1 & 0.0202 & 11.2 & 0.0224 & 11.5 & 0.023 \\
\hline TFS50T & 9.1 & 0.0182 & 9.2 & 0.0184 & 9.3 & 0.0186 & 10.1 & 0.0202 & 10.8 & 0.0216 \\
\hline TFS50TS & 9.5 & 0.019 & 9.8 & 0.0196 & 10.6 & 0.0212 & 10.7 & 0.0214 & 11.2 & 0.0224 \\
\hline TFS83.3 & 8.4 & 0.0168 & 9.1 & 0.0182 & 9.7 & 0.0194 & 9.9 & 0.0198 & 10.1 & 0.0202 \\
\hline TFS83.3D & 8.7 & 0.0174 & 9.8 & 0.0196 & 10.2 & 0.0204 & 11.1 & 0.0222 & 11.4 & 0.0228 \\
\hline TFS83.3DS & 9.3 & 0.0186 & 9.2 & 0.0184 & 10 & 0.02 & 10.4 & 0.0208 & 11.6 & 0.0232 \\
\hline TFS83.3T & 9.1 & 0.0182 & 9.4 & 0.0188 & 9.4 & 0.0188 & 10.1 & 0.0202 & 10.8 & 0.0216 \\
\hline TFS83.3TS & 9.2 & 0.0184 & 9.1 & 0.0182 & 9.2 & 0.0184 & 10.5 & 0.021 & 10.6 & 0.0212 \\
\hline
\end{tabular}


Table 6. The ratios of axial strains at ultimate load of fire damaged columns repaired with GFRP and the corresponding axial strains at ultimate load of fire damaged columns with out GFRP wrapping $\left(\varepsilon_{\mathrm{tr}} / \varepsilon_{\mathrm{t}}\right)$

\begin{tabular}{|c|c|c|c|c|c|}
\hline \multicolumn{6}{|c|}{ Cross section area aspect ratio $(\mathbf{a} / \mathbf{b})$} \\
\hline Column identification & 0.5 & 0.6 & 0.72 & 0.84 & 1 \\
\hline TFC & 1.246 & 1.264 & 1.329 & 1.384 & 1.378 \\
\hline TFCD & 1.406 & 1.375 & 1.452 & 1.616 & 1.581 \\
\hline TFCT & 1.391 & 1.403 & 1.438 & 1.493 & 1.500 \\
\hline TFS50 & 1.203 & 1.250 & 1.301 & 1.397 & 1.419 \\
\hline TFS50D & 1.304 & 1.319 & 1.329 & 1.493 & 1.527 \\
\hline TFS50DS & 1.377 & 1.333 & 1.384 & 1.534 & 1.554 \\
\hline TFS50T & 1.319 & 1.278 & 1.274 & 1.384 & 1.459 \\
\hline TFS50TS & 1.377 & 1.361 & 1.452 & 1.466 & 1.514 \\
\hline TFS83.3 & 1.217 & 1.264 & 1.329 & 1.356 & 1.365 \\
\hline TFS83.3D & 1.261 & 1.361 & 1.397 & 1.521 & 1.541 \\
\hline TFS83.3DS & 1.348 & 1.278 & 1.370 & 1.425 & 1.568 \\
\hline TFS83.3T & 1.319 & 1.306 & 1.288 & 1.384 & 1.459 \\
\hline TFS83.3TS & 1.333 & 1.264 & 1.260 & 1.438 & 1.432 \\
\hline
\end{tabular}

Table 7. The ratios of axial strains at ultimate load of fire damaged columns repaired with GFRP wrapping and the corresponding axial strains at ultimate load of undamaged columns not subjected to temperature $\left(\varepsilon_{\mathrm{tr}} / \varepsilon\right)$

\begin{tabular}{|c|c|c|c|c|c|}
\hline \multicolumn{7}{|c|}{ Cross section area aspect ratio (a/b) } & 0.72 & 0.84 & 1 \\
\hline Column identification & 0.5 & 0.6 & 1.347 & 1.347 & 1.342 \\
\hline TFC & 1.344 & 1.358 & 1.472 & 1.573 & 1.539 \\
\hline TFCD & 1.516 & 1.478 & 1.458 & 1.453 & 1.461 \\
\hline TFCT & 1.500 & 1.507 & 1.319 & 1.360 & 1.382 \\
\hline TFS50 & 1.297 & 1.343 & 1.347 & 1.453 & 1.487 \\
\hline TFS50D & 1.406 & 1.418 & 1.403 & 1.493 & 1.513 \\
\hline TFS50DS & 1.484 & 1.433 & 1.292 & 1.347 & 1.421 \\
\hline TFS50T & 1.422 & 1.373 & 1.472 & 1.427 & 1.474 \\
\hline TFS50TS & 1.484 & 1.463 & 1.347 & 1.320 & 1.329 \\
\hline TFS83.3 & 1.313 & 1.358 & 1.417 & 1.480 & 1.500 \\
\hline TFS83.3D & 1.359 & 1.463 & 1.389 & 1.387 & 1.526 \\
\hline TFS83.3DS & 1.453 & 1.373 & 1.306 & 1.347 & 1.421 \\
\hline TFS83.3T & 1.422 & 1.403 & 1.278 & 1.400 & 1.395 \\
\hline TFS83.3TS & 1.438 & 1.358 & & & \\
\hline
\end{tabular}


Table 8. Predicted ultimate loads and percentage of error compared with experimental result

\begin{tabular}{|c|c|c|c|c|c|c|c|c|c|c|}
\hline \multirow{3}{*}{$\begin{array}{c}\text { Column } \\
\text { identification }\end{array}$} & \multicolumn{10}{|c|}{ Cross section area aspect ratio $(\mathrm{a} / \mathrm{b})$} \\
\hline & \multicolumn{2}{|c|}{0.5} & \multicolumn{2}{|c|}{0.6} & \multicolumn{2}{|c|}{0.72} & \multicolumn{2}{|c|}{0.84} & \multicolumn{2}{|c|}{1.0} \\
\hline & $\begin{array}{c}\text { Predicted } \\
\text { ultimate load }\end{array}$ & $\begin{array}{c}\text { Percentage of } \\
\text { error }\end{array}$ & $\begin{array}{c}\text { Predicted } \\
\text { ultimate load }\end{array}$ & $\begin{array}{c}\text { Percentage of } \\
\text { error }\end{array}$ & $\begin{array}{c}\text { Predicted } \\
\text { ultimate load }\end{array}$ & $\begin{array}{c}\text { Percentage of } \\
\text { error }\end{array}$ & $\begin{array}{c}\text { Predicted } \\
\text { ultimate load }\end{array}$ & $\begin{array}{c}\text { Percentage of } \\
\text { error }\end{array}$ & $\begin{array}{c}\text { Predicted } \\
\text { ultimate load }\end{array}$ & $\begin{array}{c}\text { Percentage of } \\
\text { error }\end{array}$ \\
\hline TFC & 379.24 & -2.82 & 403.51 & 1.99 & 401.52 & 0.35 & 412.69 & 1.78 & 415.07 & -1.72 \\
\hline TFCD & 458.94 & -0.43 & 527.17 & 3.92 & 563.90 & -2.65 & 614.44 & 2.09 & 658.62 & -1.67 \\
\hline TFCT & 445.79 & -0.09 & 503.74 & -0.32 & 529.33 & 0.89 & 567.50 & -0.19 & 596.51 & -0.28 \\
\hline TFS50 & 370.08 & -9.84 & 420.98 & 0.57 & 446.07 & -1.06 & 482.30 & -0.06 & 512.66 & 0.44 \\
\hline TFS50D & 482.36 & 2.55 & 554.13 & -2.87 & 592.66 & -1.31 & 645.57 & 5.56 & 691.57 & 1.63 \\
\hline TFS50DS & 483.64 & 1.68 & 559.89 & -3.06 & 603.95 & 1.05 & 663.08 & 0.04 & 717.22 & 0.29 \\
\hline TFS50T & 412.18 & 0.46 & 504.34 & -1.18 & 585.77 & 0.68 & 695.31 & 14.87 & 836.07 & 34.71 \\
\hline TFS50TS & 460.07 & 2.09 & 532.76 & -3.25 & 575.09 & -9.04 & 631.99 & 0.63 & 684.59 & 0.53 \\
\hline TFS83.3 & 416.82 & -0.58 & 482.30 & 0.32 & 520.69 & 1.63 & 572.73 & -1.36 & 621.64 & 5.12 \\
\hline TFS83.3D & 511.19 & 1.50 & 580.42 & -2.10 & 612.89 & 1.08 & 659.85 & 6.32 & 696.91 & 0.61 \\
\hline TFS83.3DS & 512.52 & 0.03 & 596.93 & -0.12 & 648.06 & 0.46 & 715.56 & -0.71 & 779.18 & 0.33 \\
\hline TFS83.3T & 441.16 & 3.10 & 513.78 & -1.27 & 558.53 & -5.91 & 618.14 & 1.36 & 675.82 & 3.92 \\
\hline TFS83.3TS & 494.18 & -1.63 & 569.32 & 1.49 & 610.75 & 0.17 & 667.07 & 2.41 & 716.89 & -2.42 \\
\hline
\end{tabular}




\section{Conclusions}

In this study, the fire damaged short $\mathrm{RC}$ rectangular columns are repaired by gluing GFRP with epoxy resin in different wrap patterns. The axial load carrying capacities of repaired columns are analysed to obtain the best wrap pattern.

Wrapping of GFRP strips gave better results than wrapping as continuous sheet. Wrapping with wide strips gave better results. Staggering of strips breaks the continuous rapid propagation of GFRP tearing, hence, gave more load carrying capacity than those columns wrapped with strips one over another. The strength of column wrapped with two layers one over another or staggered is more than the strength of columns wrapped with single or triple layers. The repair with GFRP wrap is more effective for square columns. It can be concluded that fire damaged columns can be repaired effectively by GFRP wrap.

Future scope of work include the repair of columns subjected to different degrees of elevated temperature, performance of repaired column subjected to eccentric loading and evaluating various FRP materials used for repair.

\section{REFERENCES}

[1] Yaqub M, Bailey C G, Nedwell P, Axial capacity of post-heated square columns wrapped with FRP composites, Cement and Concrete Composites, Vol.33, 694-701, 2011.

[2] Tan K H and Yao Y, Fire Resistance of Reinforced Concrete Columns Subjected to 1-, 2-, and 3-Face Heating, Journal of Structural Engineering, Vol.130, No.11, 1820-1828, 2004.

[3] C Maraveas, FRP-Strengthened/Reinforced Concrete Structures exposed to fire: A review, Structural Engineering International, (2018) 500-513.

[4] Liu Lixian, Reddy D V and Sobhan K, Strengthening of Fire-damaged Columns by Cross-sectional Enlargement: A Computational Evaluation, Seventh Latin American and Caribbean Conference for Engineering and Technology (LACCEI'2009) Energy and Technology for the Americas: Education, Innovation, Technology and Practice WE1,1-11, 2009.

[5] Moudar H Z, Hashem S A, Saad M H, Mutasim S A and Bassam M Z Failure Investigation of Reinforced Concrete Columns Exposed to Fire, Engineering Sciences, Vol.39, No.1, 56-65, 2013.

[6] Joao P F, Joao R. C, Luke A B, Fire behaviour of FRP-strengthened reinforced concrete structural elements: A state-of-the-art review, Composites B, Vol.80, 198-216, 2015.

[7] Al-Kamaki Y, Al-Mahaidi R and Bennetts I, Experimental and numerical study of the behavior of heat-damaged RC circular columns confined with CFRP fabric, Composite
Structures Journal, Vol.133, 679-690, 2015.

[8] Sai L N K and Sai Ram K S, Strengthening of axially loaded reinforced concrete rectangular columns with GFRP strips, Materials Today Proceedings, Vol.18, No.7, 3758-3765, 2019.

[9] Sai Madupu, L.N.K., Sai Ram, K.S, Performance of axially loaded reinforced concrete rectangular columns strengthened with GFRP strips, Materials Today Proceedings, Vol.43, 1784-1791, 2020.

[10] Lam L and Teng J G, Design-Oriented Stress-Strain Model for FRP-Confined Concrete In Rectangular Columns, Journal Of Reinforced Plastics And Composites, Vol.22, No.13, 1149-1186, 2003.

[11] Chen J F, Li S Q and Bisby L A, Factors Affecting the Ultimate Condition of FRP-Wrapped Concrete Columns, Journal of Composites for Construction, Vol.17, No.1, 67-78, 2013.

[12] Alper llki, Onder Peker, Emre Karamuk, Cem Demir, and Nahit Kumbasar, FRP Retrofit of Low and Medium Strength Circular and Rectangular Reinforced Concrete Columns, Journal of Materials in Civil Engineering, Vol.20,No.2, 169-188, 2008.

[13] Silva,Manuel A. G.,Rodrigues, Carlos C. 2006. Journal Materials in Civil Engineering. Vol.10.1061, 334 - 342, 2006.

[14] Sultan Erdemli Gunaslan., Halim Karasin., Dicle University, Faculty of Engineering, Turkey, Diyarbakır European Scientific Journal, Vol.10, No.3, 1857- 7431, 2014.

[15] Manish kumar Tiwari., Rajiv Chandak., Yadav, R.K. International Journal of Engineering Research and Application, Vol.4, No.4, 50-54, 2014.

[16] Azadeh Parvin, David Brighton, Polymers, Vol.6, 2073-4360, 2014.

[17] Saadatmanesh, H., Ehsani,M. R., Li, M. W., ACI Structural Journal, Vol91, No.4, 434 - 449, 1994.

[18] Promis,G., Ferrier,E.,Hamelin, P., Composite Structures, Vol.88, 367 - 379, 2009.

[19] Antonio De Luca, M. ASCE., Fabio Nardone., Fabio Matta, A.M. ASCE., Antonio Nanni, F., Gian Piero Lignola., and Andrea Prota. Journal of Composite Construction, Vol.15, No.1, 112-123, 2008.

[20] Riad Benzaid, Nasr-Eddine Chikh \& Habib Mesbah, Journal of Civil Engineering Management, Vol.14, No.2, 115-120, 2008.

[21] Silvia Rocca, Nestore Galati, and Antonio Nanni, Journal of Composite Construction, Vol.12, 80-92, 2008.

[22] Toutanji, H. and Balaguru, P., Journal of Materials in Civil Engineering, Vol.10, No.1, 52-57, 1998.

[23] Omar Challal, MohsenShahawy and Munzer Hassan., Journal of Composites for Construction, Vol.7, No.3, 200-208, 2003.

[24] Cabral-Fonsecaa S, Correiab, J.R., Custódioa, J.H., Silvaa, M., Machadoa, A.M., Sousab, Journal of Adhesion and 
Adhesives, Vol.83, 153-167, 2018.

[25] Mukhtar, Faisal M., Faysal, Rayhan M, Construction and Building Materials, Vol.169, 877 - 887, 2018.

[26] Yanlei Wang, PuLiu, QiCao, GuipengChen, BaolinWan, ZitaoWei, Yu-LeiBai, Comparison of monotonic axial compressive behavior of rectangular concrete confined by
FRP with different rupture strains, Construction and Building Materials, Vol. 299, 6-7, 2021.

[27] Manar Takla, Ihssan Tarsha, Effect of Temperature on Carrying Capacity of Concrete Columns Confined with Multi-layers of CFRP, Jordan Journal of Civil Engineering, Vol. 14, No. 1, 2020. 